\title{
Development of an ELISA using anti-idiotypic antibody for diagnosis of opisthorchiasis
}

\author{
Aitbay K. Bulashev ${ }^{1}$, Sergey N. Borovikov ${ }^{1}$, Shynar S. Serikova ${ }^{1}$, Zhanbolat A. Suranshiev ${ }^{1}$, Vladimir S. Kiyan $^{1}$ \\ and Saule Z. Eskendirova ${ }^{2}$
}

${ }^{1}$ Faculty of Veterinary and Livestock Technology, S. Seifullin Kazakh Agro-Technical University, Astana, Kazakhstan;

${ }^{2}$ Cell Engineering Laboratory, National Centre for Biotechnology of the Republic of Kazakhstan, Astana, Kazakhstan

\begin{abstract}
Monoclonal antibody specific for an epitope of cretory-secretory antigen protein of Opisthorchis felineus (Rivolta, 1884) (Trematoda: Opisthorchiidae) with a molecular weight of $28 \mathrm{kDa}$ was used in a sandwich enzyme-linked immunosorbent assay (ELISA) for immobilisation of liver fluke specific antigen to the solid phase. Examination of human sera by this ELISA compared with commercial assays demonstrated that the monoclonal antibody epitope is located within this significant parasite protein. Anti-idiotypic antibody specific for the paratope of this monoclonal antibody was obtained by a hybridoma technique. Mimicking an epitope of excretory-secretory antigen of $O$. felineus, it had the capacity to bind specific antibody and elicit an antibody response. The value of anti-idiotypic antibody as a substitute for the liver fluke antigen was tested by ELISA using serum samples of infected dogs. Anti-idiotypic antibody proved to be of value in both an indirect-ELISA and a competitive-ELISA for diagnosis of opisthorchiasis. Mature trematodes were isolated from all infected animals. The faecal egg counts were negative in dogs with a relatively small number of parasites, despite finding antibodies in serum by ELISA. Substitution of parasite antigen with anti-idiotype avoids the use of experimental animals and also reduces time-consuming steps of antigen preparation.
\end{abstract}

Keywords: Opisthorchis felineus, excretory-secretory antigen, antigenicity, immunogenicity, monoclonal antibody, polyclonal antibody

Opisthorchis felineus (Rivolta, 1884) (Trematoda: Opisthorchiidae) is a trematode that is transmitted to humans through the consumption of raw or undercooked fish of the family Cyprinidae. Infection has been documented in humans and/or animals in 13 countries of the European Union (Pozio et al. 2013). The disease is endemic and represents a public health problem also in the Russian Federation, Ukraine, Belarus and Kazakhstan (WHO 1995). Most people with opisthorchiasis have nonspecific symptoms, but chronic infections are linked to severe complications and are associated with cholangiocarcinoma (Armignacco et al. 2013).

Faecal examination for detection of parasite eggs is the best way to reach an accurate diagnosis of opisthorchiasis, but its sensitivity depends on the choice of examination, the intensity of infection and the experience of the microscopist (Johansen et al. 2010). Moreover, eggs of trematodes cannot be differentiated by microscopic examination (Toledo et al. 2012). Hence, the detection of parasite-specific antibody responses has been considered as an informative approach to diagnosis of this invasive disease (Sripa and Kaewkes 2000, Traverso et al. 2012).

Serological studies using different preparations from species of Opisthorchis have indicated that metabolic anti- gen was the most effective for diagnosis of opisthorchiasis by the passive hemagglutination test and an enzyme-linked immunosorbent assay (ELISA) (Teplukhin et al. 1990). The efficiency of an ELISA kit containing parasite somatic antigens (SA) has been validated by the detection of circulating immune complexes (CIC) using 270 sera from patients (Starkova et al. 2011). Sensitivity and specificity of the kit were $87 \%$ and $98 \%$, respectively.

An ELISA using excretory-secretory antigen (ES-Ag) showed acceptable sensitivity, repeatability, reproducibility and specificity for the detection of infection with $O$. felineus in humans (Gómez-Morales et al. 2013). However, using either SA or ES-Ag of liver flukes in an ELISA does not always provide reliable results, because of cross-reactions with other pathogens (Lepekhin et al. 1990, Amornpunt et al. 1991, Sakolvaree et al. 1997).

An alternative approach is to use anti-idiotypic antibodies (AIab), representing 'internal images' of the antigen epitopes. Affinity-purified AIab have been shown to be useful in monitoring the isolation of target antigens of hybridoma anti-schistosome antibodies in a competitive radioimmunoassay (Mitchell et al. 1983). The suitability of monoclonal AIab has been proved in detecting antibodies against Schistosoma japonicum Katsurada, 1904 in human

Address for correspondence: A.K. Bulashev, Faculty of Veterinary and Livestock Technology, S. Seifullin Kazakh Agro-Technical University, Prospect Pobedy 62, 010011, Astana, Kazakhstan. Phone:+7 71723175 47; Fax: :+7 71723160 72; E-mail: aytbay57@mail.ru 
sera (Wu et al. 1993). The possibility of using AIab as an alternative immunoreagent has also been established in bovine cysticercosis (Hayunga et al. 1992). AIab have also been used in the improvement of methods for detecting bacterial (Laferrière et al. 1993, An et al. 1997) and viral infections (Zhou and Huang 1995, Li et al. 2005). However, the value of AIab to antibodies specific for liver flukes has not been explored. The aim of the present study was to obtain AIab specific for the paratope of monoclonal antibodies (MAb) toward

s excretory-secretory antigen of $O$. felineus $(O$. felineus ES-Ag) and to use them in the development of an assay for the serologic diagnosis of opisthorchiasis.

\section{MATERIALS AND METHODS}

Fish. Freshwater fish of the family Cyprinidae, 221 ide - Leuciscus idus (Linnaeus), 55 bream - Abramis brama (Linnaeus), 26 tench - Tinca tinca (Linnaeus) and 12 crucian carp Carassius carassius (Linnaues), were collected from Sholak and Karazhar Lakes in the Korgalzhyn District of Akmola Region, Kazakhstan. They were transported on ice to the laboratory and immediately individually tested for the presence of metacercariae of $O$. felineus by the muscle compression method (Thu et al. 2007). Infected specimens were selected for feeding experimental dogs on the same day.

Experimental animals. Experimental animals were housed in the vivarium of S. Seifullin Kazakh Agro-Technical University (KATU), and their use and care were approved by the Animal Ethics Committee of Veterinary Medicine Faculty of KATU. Five outbred female dogs were routinely immunised at 3 months of age (Vetanimalcenter, Moscow, Russia) and dewormed with an anthelmintic (Vermis-EX, Aulendorf, Germany). Four dogs were infected by feeding skinned fish fillets containing metacercariae of $O$. felineus every 5-7 days over the course of two months and one dog served as control. The infection of dogs was carried out without taking into account the number of larvae. From three weeks post infection onward, stool samples from each dog were collected weekly for microscopic examination by conventional Fülleborn's method (Fülleborn 1920). Three months post infection, experimental dogs were euthanised for postmortem examination by the intramuscular injection of xylazine (Alfasan International B.V., Woerden, Netherlands) ( $2 \mathrm{mg} / \mathrm{kg}$ body weight) and an intravenous overdose of propofol (VIK, Moscow, Russia) (15 mg/kg body weight).

Mice 4-6 weeks of age were used to produce hybridomas by harvesting immune splenocytes stimulated against ES-Ag and AIab ( 2 and 6 mice, respectively). Six syngeneic mice were used for in vivo cultivation of hybridomas to produce ascitic fluid. Mice were euthanised by cervical dislocation before isolation of the spleens and/or suction of peritoneal fluid. Outbred mice 8-10 weeks of age were used to study the antigenicity and immunogenicity of parasite ES-Ag and AIab (4 and 9 mice, respectively).

Antigens. A piece of canine liver with gall bladder was removed and washed twice in warm $\left(37^{\circ} \mathrm{C}\right)$ phosphate-buffered saline (PBS), $\mathrm{pH}$ 7.2, in a Petri dish. The gall bladder and bile ducts were opened with small scissors and gentle pressure was applied to the liver to release the liver flukes. Parasites were transferred to $50 \mathrm{ml}$ tubes (Falcon, Radnor, USA) and washed 4-5 times in PBS supplemented with penicillin (Simbirskaya veterinary company,
Ulyanovsk, Russia) (500 units/ml) and streptomycin (Himfarm, Shymkent, Kazakhstan) $(500 \mathrm{mg} / \mathrm{ml})$. Recovered liver flukes were used to obtain SA and/or accumulation of ES-Ag by cultivation in nutrient medium RPMI-1640 supplemented with $1 \mathrm{M}$ HEPES, $200 \mathrm{mM}$ L-glutamine, $100 \mathrm{mM}$ sodium pyruvate (all from Sigma-Aldrich, St. Louis, USA), and 5000 units of penicillin/streptomycin. Isolated $O$. felineus were cultured at the rate of 30 specimens per $10 \mathrm{ml}$, and nutrient medium was changed every $24 \mathrm{~h}$ over 4 days. A previously described method was used for the preparation of O. felineus ES-Ag (Bulashev et al. 2011) and ES-Ag of the cestode Echinococcus granulosus (Batsch, 1786) (Bulashev et al. 2012). Preparation of ES-Ag included aspirating the culture supernatant in $48-96 \mathrm{~h}$, centrifugation at $10000 \times \mathrm{g}$ for $10 \mathrm{~min}$, membrane filtration, dialysis against distilled water, and concentrating the liquid to 10 times. SA of $O$. felineus, Metorchis bilis (Braun, 1790) (both Trematoda) and cysticercus tenuicollis, i.e. larval stage - metacestode of Taenia hydatigena Pallas, 1766 - have been prepared in our previous research (Borovikov et al. 2010). Helminths were triturated in pure form immediately after freezing with liquid nitrogen, then resuspended in PBS and filtered through a $0.45 \mu \mathrm{m}$ membrane filter.

Mouse IgM and its $F(a b)$, fragment specific to $O$. felineus ES-Ag, obtained by hybridoma technique were used as antigens to obtain AIab modeling parasite epitopes. Fragmentation of IgM was carried out by pepsin digestion using Pierce IgM Fragmentation kit (Thermo Scientific, Rockford, USA). The IgM $F(a b)_{2}$ fragment was conjugated with colloidal gold (Sigma-Aldrich) in order to increase its immunogenicity (Dykman et al. 2004). To prepare conjugate, $1.0 \mathrm{ml}$ of immunoglobulin solution with the selected concentration was added dropwise to $10 \mathrm{ml}$ of colloidal gold solution, $\mathrm{pH} 7.0-7.5$, stirring for $30 \mathrm{~min}$ at room temperature. Then $1 \%$ bovine serum albumin (BSA) was added to the solution to a final concentration of $0.25 \%$. Unbound immunoglobulin was removed by centrifugation at $11000 \times g$ for $30 \mathrm{~min}$. The supernatant was discarded and the precipitate was dissolved in a buffer containing $20 \mathrm{mM}$ Tris$\mathrm{HCl}, \mathrm{pH} 8.2$, and $1 \% \mathrm{BSA}$.

Serum and polyclonal antibodies (pAb). At the end of the experiment, whole blood was collected from dogs in a covered test tube and left undisturbed at room temperature to clot for 30 $\mathrm{min}$. The clot was removed by centrifuging at $1000 \times g$ for $10 \mathrm{~min}$ in a refrigerated centrifuge. Serum was immediately transferred into a clean polypropylene tube using a Pasteur pipette. A portion of serum was apportioned into $0.5 \mathrm{ml}$ aliquots, stored at $-70^{\circ} \mathrm{C}$ and another portion was sequentially subjected to ammonium sulfate precipitation and gel filtration chromatography (Pharmacia, Uppsala, Sweden) to prepare anti-O. felineus $\mathrm{pAb}$ and immunoglobulin fraction from the control dog.

Antiserum to $O$. felineus ES-Ag was prepared according to the following protocol. Outbred mice were given intraperitoneal injections of $0.1 \mathrm{mg}$ of the antigen in $0.1 \mathrm{ml}$ of incomplete Freund's adjuvant (Sigma-Aldrich) on the first day of immunisation. Then, on days 7,11, 12 and 13, mice were injected with $0.1 \mathrm{mg}$ antigen in PBS, $\mathrm{pH}$ 7.2-7.4. Three days after the last immunisation, mice were bled from the tail vein into microfuge tubes (Isolab, Wertheim, Germany). Blood was centrifuged at $1000 \times g$ for $10 \mathrm{~min}$, and antiserum was transferred to a clean tube.

Serum samples were taken between days 3 and 27 after the 13 day immunisation to study immunogenicity of $O$. felineus ES- 
$\mathrm{Ag}$ and/or AIab from outbred mice of another group, immunised with these antigens under the same scheme.

Serum samples of humans suspected of contracting infectious diseases were kindly provided by Astana Infectious Diseases Hospital, Kazakhstan in compliance with patient confidentiality.

Preparation of MAb and AIab. Balb/c mice were immunised with $O$. felineus ES-Ag according to the protocol for obtaining antiserum as described above. The serum antibody titres were determined by ELISA on day 3 after the last immunisation. The assay was carried out in flat-bottomed polystyrene 96-well microtitre plates (Corning Inc., New York, USA) by a standard procedure. Briefly, the wells were filled with the relevant antigen $(5.0 \mu \mathrm{g} / \mathrm{ml})$ in bicarbonate buffer (BCB), $\mathrm{pH}$ 9.6. Sera were diluted in PBS with $0.05 \%$ Tween-20 (PBS-T) starting with the titre of $1: 100$. Immune complexes were revealed by using peroxidase-conjugated goat anti-mouse $\operatorname{IgG}(\mathrm{H}+\mathrm{L})$ (Jackson Immuno Research, West Grove, USA) and 3.3',5.5'-tetramethylbenzidine (Sigma-Aldrich). The optical density (OD) value was obtained by reading the reaction at $492 \mathrm{~nm}$ using an ELISA plate microtitre reader (Asys Hitech GmbH, Eugendorf, Austria).

The same method was used for immunisation of Balb/c mice with IgM and/or its $F(a b)_{2}$-fragments specific for $O$. felineus ES-Ag to get AIab. To determine the intensity of AIab production by immune mice, the solid phase was filled with canine anti-O. felineus pAb $(5.0 \mu \mathrm{g} / \mathrm{ml})$ in $\mathrm{BCB}, \mathrm{pH} 9.6$, at $4{ }^{\circ} \mathrm{C}$ overnight. After blocking active sites of polystyrene wells with $1 \%$ BSA, serum samples were added and the plate was incubated for $1 \mathrm{~h}$ at $37^{\circ} \mathrm{C}$. The titre of polyclonal AIab was detected by peroxidase-conjugated goat anti-mouse $\operatorname{IgG}(\mathrm{H}+\mathrm{L})$ and its substrate. The spleens of mice with high titres of serum antibodies towards the antigens were removed for isolation of immune lymphocytes.

Hybridomas were obtained by fusion of X63-Ag8.653 myeloma cells with lymphocytes of immunised mice with polyethylenglycol 4000 (Fluka BioChemika, Buchs, Switzerland) by the hybridoma technique (Kohler and Milstein 1975). The fusion mixture was directly distributed onto 96-well culture plates (PRSRanreac, Castellar del Valles, Barcelona, Spain) with feeder cells containing HAT-medium (Sigma-Aldrich). For culturing hybridomas, RPMI-1640 medium was used containing ingredients as above and $10 \%$ heat inactivated fetal calf serum (Sigma-Aldrich).

Hybridomas were tested for antibody production by testing their supernatants between 10 and 20 days post-fusion. Indirect-ELISA was used to determine the clones producing $\mathrm{MAb}$ against $O$. felineus $\mathrm{ES}-\mathrm{Ag}$ according to the standard procedure. The presence of AIab in hybridoma supernatant was established by sandwich-ELISA with the help of canine anti-O. felineus $\mathrm{pAb}$ as described above. The availability of immune complexes was detected in parallel by using peroxidase-conjugated goat anti-mouse $\operatorname{IgG}(\mathrm{H}+\mathrm{L})$ and peroxidase-conjugated goat anti-mouse $\operatorname{IgM}$ ( $\mu$ chain specific) (Jackson Immuno Research). Hybridomas were considered positive if the supernatant OD value was higher at least twice the OD value of the control culture fluid obtained from the myeloma cells. Selected crude clones were sub-cloned by limiting dilution (Waldmann and Lefkovits 1984).

Preparative amounts of MAb and AIab were obtained by culturing hybridoma clones in the intraperitoneal cavity of syngeneic mice pretreated with pristane (Sigma-Aldrich). Ascitic fluid was clarified by centrifugation and antibodies were sequentially purified by saturated solution of ammonium sulfate (Appli Chem
Panreac ITW Companies, Darmstadt, Germany) and gel filtration chromatography. Protein concentration was determined by the conventional Coomassie blue method. Conjugation of MAb with horseradish peroxidase (Sigma-Aldrich) was carried out by the periodate method (Nakane and Kawaoi 1974).

Isotyping and definition of antibody affinity. Immunoglobulin classes of MAb and AIab were determined by indirect ELISA using Mouse Monoclonal Antibody Isotyping Reagents (Sigma-Aldrich). Antibody affinity was established by a non-competitive immunoassay as described previously (Beatty et al. 1987).

Western blot analyses. Sodium dodecyl sulfate-polyacrylamide gel electrophoresis (SDS-PAGE) was performed by a standard procedure (Laemmli 1970). The resolved proteins were transferred onto nitrocellulose membranes (Watman Nytran Supercharge Aldrich, St. Louis, USA) and immunoblotting has been carried out as described previously (Towbin et al. 1979).

Commercial kits. Commercial kits Opisthorch-IgM-ELISABEST, Opisthorch-IgG-ELISA-BEST and Opisthorch-CIC-ELISA-BEST (Vector, Novosibirsk, Russia) designed for serological detection of opisthorchiasis were used in accordance with the manufacturer's instructions.

Sandwich-ELISA for the detection of $O$. felineus ES-Ag specific antibodies in human sera. Briefly, a 96-well microtitre plate was coated with MAb specific to parasite ES-Ag in BCB, $\mathrm{pH} 9.6$, at $4{ }^{\circ} \mathrm{C}$ overnight. After washing 3 times with PBS-T, the active centres of the wells were neutralised with $1 \% \mathrm{BSA}$ and the appropriate antigen was added. Non-specific components were removed by washing and human serum samples were applied. The presence of specific antibodies was detected in parallel using peroxidase-conjugated goat anti-human IgG $(\mathrm{H}+\mathrm{L})$ (Jackson Immuno Research, West Grove, USA) and peroxidase-conjugated goat anti-human IgM ( $\mu$ chain specific) (Sigma-Aldrich).

Sandwich-ELISA for the detection of CIC in human serum. MAb to O. felineus ES-Ag were used to immobilise CIC to the solid-phase. Human serum samples were added into the wells sensitised with MAb and the presence of immune complexes was determined by applying peroxidase-conjugated goat anti-human IgG.

Definition of AIab antigenicity by indirect-ELISA. Microtitre plate wells were coated with AIab $F(a b)_{2}$ fragments at the concentration of $5.0 \mu \mathrm{g} / \mathrm{ml}$ in $\mathrm{BCB}, \mathrm{pH} 9.6$, overnight at $4{ }^{\circ} \mathrm{C}$. Then, they were washed with PBS and PBS-T, pH 7.2. Antiserum to O. felineus $\mathrm{ES}-\mathrm{Ag}$ was diluted in 8 wells pretreated with $1 \% \mathrm{BSA}$, starting with $1: 100$ in PBS-T. After incubation at $37^{\circ} \mathrm{C}$ for $1 \mathrm{~h}$, the results of immunoassay were developed by peroxidase-conjugated goat anti-mouse IgG (Fc-specific) (Sigma-Aldrich) and its substrate. Serum of the non-immunised mouse was used as a control. ELISA results were considered positive if the OD value of the well with serum sample from an experimental animal was higher at least twice the OD value of the control well.

Studying AIab antigenicity by sandwich-ELISA. Microtitre plate wells were sensitised with canine anti-O. felineus $\mathrm{pAb}$ $(5.0 \mu \mathrm{g} / \mathrm{ml})$ in $\mathrm{BCB}, \mathrm{pH} 9.6$, overnight at $4{ }^{\circ} \mathrm{C}$, and blocked by $1 \%$ BSA. Control wells were covered with immunoglobulin of the control dog. AIab at a concentration of $1.0 \mathrm{mg} / \mathrm{ml}$ were diluted in the wells, starting with $1: 100$ or $10.0 \mu \mathrm{g} / \mathrm{ml}$ in PBS-T. The results of the test were developed by peroxidase-conjugated goat anti-mouse IgM and tetramethylbenzidine. 
Table 1. The results of microscopic examination of dogs infected with Opisthorchis felineus (Rivolta, 1884).

\begin{tabular}{lccc}
\hline $\begin{array}{l}\text { Number } \\
\text { of dogs }\end{array}$ & $\begin{array}{c}\text { Presence (+) or } \\
\text { absence (-) of eggs in } \\
\text { stool samples }\end{array}$ & $\begin{array}{c}\text { Number of parasites } \\
\text { recovered from the } \\
\text { gallbladder and bile } \\
\text { ducts }\end{array}$ & $\begin{array}{c}\text { Antibody titres } \\
\text { against Opisthorchis } \\
\text { felineus ES-Ag by } \\
\text { indirect-ELISA }\end{array}$ \\
\hline 1 & - & 41 & $1: 400$ \\
2 & + & 450 & $1: 800$ \\
3 & - & 74 & $1: 200$ \\
4 & + & 561 & $1: 800$ \\
\hline
\end{tabular}

Table 2. Characteristics of hybridoma subclones.

\begin{tabular}{lcccccc}
\hline & & \multicolumn{2}{c}{$\begin{array}{c}\text { Productivity } \\
\text { of hybridomas } \\
(\mathrm{mg} / \mathrm{ml})\end{array}$} & \multicolumn{2}{c}{$\begin{array}{c}\text { MAb titres by ELISA } \\
\text { against } \text { Opisthorchis } \\
\text { felineus } \text { ES-Ag }\end{array}$} \\
\cline { 4 - 8 } $\begin{array}{l}\text { Designation } \\
\text { of subclones }\end{array}$ & $\begin{array}{c}\mathrm{MAb} \\
\text { isotypes }\end{array}$ & $\begin{array}{c}\text { MAb } \\
\text { affinity }\end{array}$ & & in vitro in vivo & $\begin{array}{c}\text { superna- } \\
\text { tant }\end{array}$ & $\begin{array}{c}\text { ascites } \\
\text { fluid }\end{array}$ \\
\hline 1B2E4 & IgG1 & $6 \times 10^{-5} \mathrm{M}$ & 0.03 & 4.0 & $1: 16$ & $1: 3200$ \\
4B3D9 & IgM & $6 \times 10^{-5} \mathrm{M}$ & 0.13 & 6.0 & $1: 32$ & $1: 6400$ \\
\hline
\end{tabular}

Determination of AIab and ES-Ag immunogenicity. The wells of a 96-well microtitre plate were filled with ES-Ag $(5.0 \mu \mathrm{g} / \mathrm{ml})$ in $\mathrm{BCB}, \mathrm{pH} 9.6$, at $4{ }^{\circ} \mathrm{C}$ overnight. After blocking active sites of the solid phase with $1 \%$ BSA, 2-fold dilutions of immune sera to $O$. felineus ES-Ag or AIab were added to 8 wells, starting with a titre of $1: 100$ and incubated at $37^{\circ} \mathrm{C}$ for $1 \mathrm{~h}$. Subsequent stages of ELISA were performed according to the standard procedure. Serum of the control mouse was used as a control.

Serologic testing of dogs for opisthorchiasis by indirect ELISA. A microtitre plate was filled with AIab $(5.0 \mu \mathrm{g} / \mathrm{ml})$ in $\mathrm{BCB}, \mathrm{pH}$ 9.6. After incubation at $37^{\circ} \mathrm{C}$ for $1 \mathrm{~h}$, the plate was washed with PBS and PBS-T, pH 7.2, blocked by adding $1 \%$ BSA, and incubated in the same mode. After another washing, $1: 100$ diluted serum sample was added in duplicate and the plate was incubated at $37^{\circ} \mathrm{C}$ for $1 \mathrm{~h}$. After washing, peroxidase-conjugated rabbit anti-dog IgG (whole molecule) (Sigma-Aldrich) was added, and the plate was kept in the same mode. Finally, the ELISA results were read by the standard procedure after a last wash.

Serologic testing of dogs for opisthorchiasis by competitive-ELISA. The wells of a microtitre plate were filled with AIab $(5.0 \mu \mathrm{g} / \mathrm{ml})$ in $\mathrm{BCB}$ at $4{ }^{\circ} \mathrm{C}$ overnight. The active part of the solid phase was blocked by $1 \%$ BSA for $1 \mathrm{~h}$ and the wells washed with PBS and PBS-T, pH 7.2. Then $0.03 \mathrm{ml}$ of PBS-T and $0.07 \mathrm{ml}$ of serum samples obtained from experimental dogs were added to each well, and the plate was incubated at room temperature for $1 \mathrm{~h}$, treated with washing buffers. Further, the working solution of peroxidase-conjugated MAb 4B3D9 was applied to each well, and the plate was incubated at room temperature for $20 \mathrm{~min}$. Determination of the degree of substrate cleavage by enzyme was performed by the standard technique. Each serum sample was studied in triplicate. Competitive-ELISA results were considered positive if OD value in the test well was less than twice the OD value for the negative control serum.

Statistical analysis was performed to determine the significance of differences between antibody titres (Sayduldin 1992).

Hybridoma strains 4B3D9 and 4H10 have been deposited in the Collection of Microorganisms of Scientific Research Institute for Biological Safety Problems of the Ministry of Education and

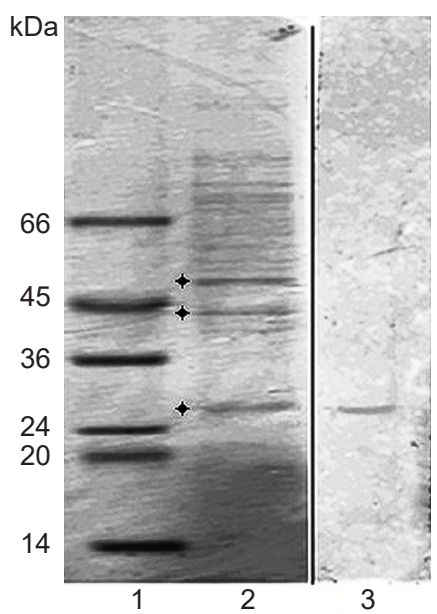

Fig. 1. Western blot using Mab 4B3D9 to Opisthorchis felineus ES-Ag. Column 1: molecular markers; column 2: electrophoregram of liver fluke ES-Ag; column 3: the protein of liver fluke ES-Ag specific to Mab 4B3D9 (stars - level of the protein bands of liver fluke ES-Ag whose molecular weights correspond to 50, 44 and $28 \mathrm{kDa}$ ).

Science of the Republic of Kazakhstan (Gvardeisky village, Korday District, Zhambyl, Kazakhstan) and they can be transferred to third parties through a material transfer agreement.

\section{RESULTS}

A total of 314 freshwater fish of four species (Leuciscus idus, Abramis brama, Tinca tinca, Carassius carassius) of the family Cyprinidae were collected. Metacercariae of liver fluke were found only in ides from Sholak Lake with prevalence of $26 \%$.

Parasite eggs were detected in faeces of two of four infected dogs six weeks after infection and eggs were expelled to the end of the experiment. ELISA results were positive and mature parasites were isolated from both infected dogs and identified as Opisthorchis felineus based on their morphology (Table 1).

The final concentration of parasite ES-Ag before each change of medium was in the range of $15-30 \mu \mathrm{g} / \mathrm{ml}$. Hybridisation of myeloma cells and lymphocytes stimulated with $O$. felineus ES-Ag produced 37 positive hybridomas. During culturing and testing in ELISA by using antigens of Cysticercus tenuicollis, Metorchis bilis and Echinococcus granulosus, two clones stably producing MAb specific to $O$. felineus were selected. The selected hybridomas were subjected to cloning and one of the subclones from each hybridoma with maximum antibody activity determined by ELISA was selected for further study (Table 2).

MAb 4B3D9 obtained from ascites fluid bound to $O$. felineus ES-Ag and SA with a high specificity as detected by dilutions to $1: 6400$ and $1: 800$, respectively. It did not react with antigens of the other helminths.

Protein analysis by SDS-PAGE indicated the presence of three predominant protein bands in the structure of O. felineus ES-Ag with molecular weights of 50, 44 and $28 \mathrm{kDa}$. Immunoblotting analyses confirmed the specificity of MAb 4B3D9 to the protein band with a molecular weight of $28 \mathrm{kDa}$ (Fig. 1). 
Table 3. The intensity of antibody production against MAb.

\begin{tabular}{|c|c|c|c|c|c|}
\hline $\begin{array}{l}\text { Group } \\
\text { number }\end{array}$ & $\begin{array}{l}\text { Number } \\
\text { of mice }\end{array}$ & Type of MAb 4B3D9 antigen & $\begin{array}{l}\text { Average antibody } \\
\text { titres }\end{array}$ & $\begin{array}{l}\text { Relative accuracy of the } \\
\text { average titres }\end{array}$ & $\mathrm{P}$ \\
\hline 1 & 3 & $\begin{array}{l}F(a b) \text { fragment of MAb, conjugated with } \\
\text { colloidal gold }\end{array}$ & $1: 5200$ & $+26.6 \% ;-21.1 \%$ & \multirow{2}{*}{$<0.05$} \\
\hline 2 & 3 & $\begin{array}{l}\text { Whole molecule of MAb specific for an } \\
\text { epitope of Opisthorchis felineus ES-Ag }\end{array}$ & $1: 490$ & $+26.6 \% ;-21.1 \%$ & \\
\hline
\end{tabular}

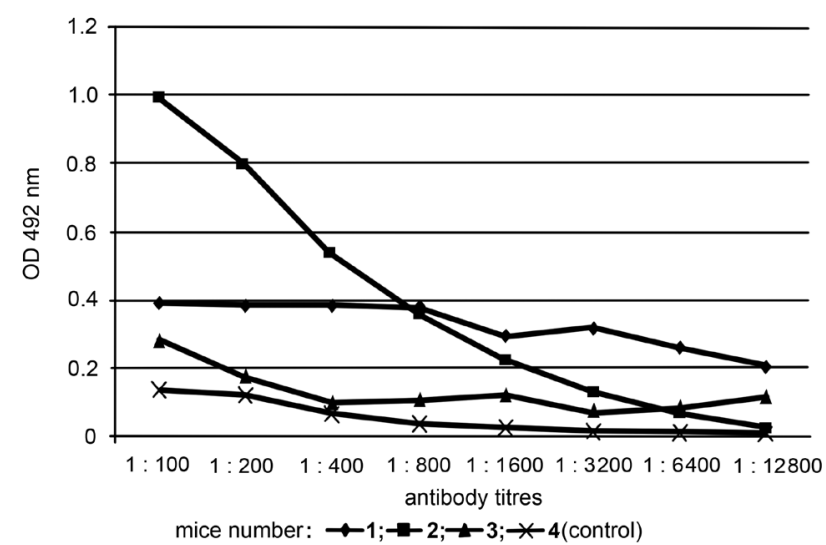

Fig. 2. Antibodies titres in serum of immune mice against AIab $4 \mathrm{H} 10$ by indirect-ELISA.

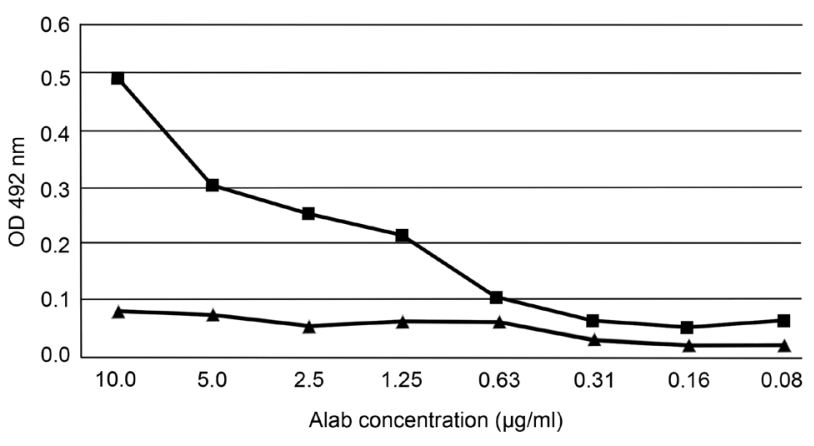

- Canine pab against O.felineus + Alab 4H10 + antimouse conjugate - Intact dog's Ig + Alab 4H10 + antimouse conjugate

Fig. 3. Antigenicity of AIab $4 \mathrm{H} 10$ in sandwich-ELISA.

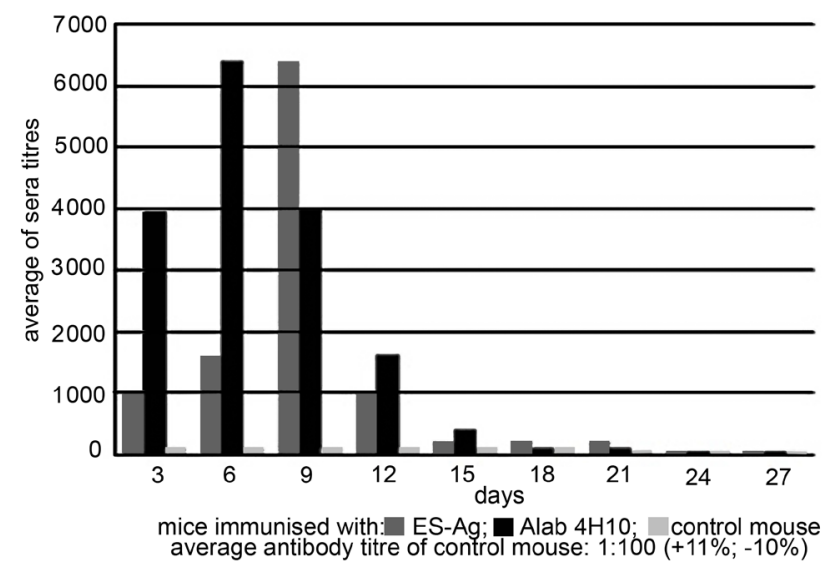

Fig. 4. Immunogenicity of AIab and Opisthorchis felineus ES-Ag for mice by indirect-ELISA.
The value of the MAb-based sandwich immunoassay developed at KATU was validated in parallel with the commercial kits for the detection of IgM- and IgG-antibodies and CIC. Serum samples from 141 human patients suspected of contracting infectious diseases were subjected to serologic analysis.

Kit Opisthorch-IgM-ELISA-BEST did not give positive readings, but kit Opisthorch-IgG-ELISA-BEST revealed the presence of specific antibodies in sera of 4/141 (3\%) patients. The KATU ELISA confirmed all positive results of the latest kit and additionally identified one more person with specific antibodies to O. felineus. The KATU ELISA and its commercial analogue detected CIC in the blood samples obtained from the same four patients. It is important to emphasise that IgG-antibodies and CIC were not detected simultaneously in the blood samples. Thus, MAb 4B3D9 has an affinity for the epitope of a diagnostically valuable protein and therefore it was used as the idiotype (antigen) for the hybridoma technique to obtain AIab.

The $F(a b)_{2}$ fragment of MAb, conjugated with colloidal gold, was more immunogenic than the whole molecule. For instance, the average antibody titre of mice from the first group was $1: 5200$, which was significantly higher than the second group: $1: 490(p<0.05)$ (Table 3$)$.

As a result of two hybridisations using lymphocytes stimulated with the conjugated $F(a b)_{2}$-fragment, we obtained 292 clones and within this pool 18 clones $(6 \%)$ produced antibodies to idiotype of the MAb used. A single clone from the positive hybridomas was selected (4H10) and subjected to cloning. Injection of this clone into the peritoneal cavity of syngeneic mice induced formation of ascitic fluid containing AIab with a titre of $1: 800$. The antibody produced by clone $4 \mathrm{H} 10$ were $\operatorname{IgM}$ with affinity of $2.6 \times 10^{-9} \mathrm{M}$.

AIab was recognised as trematode-specific antigen by serum antibodies of three mice immunised with $O$. felineus ES-Ag, i.e. it possessed antigenic properties (Fig. 2). AIab produced by selected hybridoma strain $4 \mathrm{H} 10$ was specific to antibodies of infected dogs that show interaction up to the concentration of $0.63 \mu \mathrm{g} / \mathrm{ml}$ (Fig. 3).

On day three post-immunisation, the average antibody titre in sera of mice immunised with ES-Ag was in the range of 1 : 980, whereas stimulation of the immune system by AIab caused enhanced production of specific antibodies up to a titre of $1: 3940(\mathrm{P}<0.05)$ (Fig. 4). Despite some fluctuations in the antibody titre of the latter group, it remained at the same level on days $6(1: 6400)$ and 9 post-immunisation $(1: 3940 ; \mathrm{P}>0.05)$, whereas the median titre of mice immunised with ES-Ag during this period has been increased significantly $(\mathrm{P}<0.01)$. The maximum antibody titres against AIab and ES-Ag were observed on days 6 and 


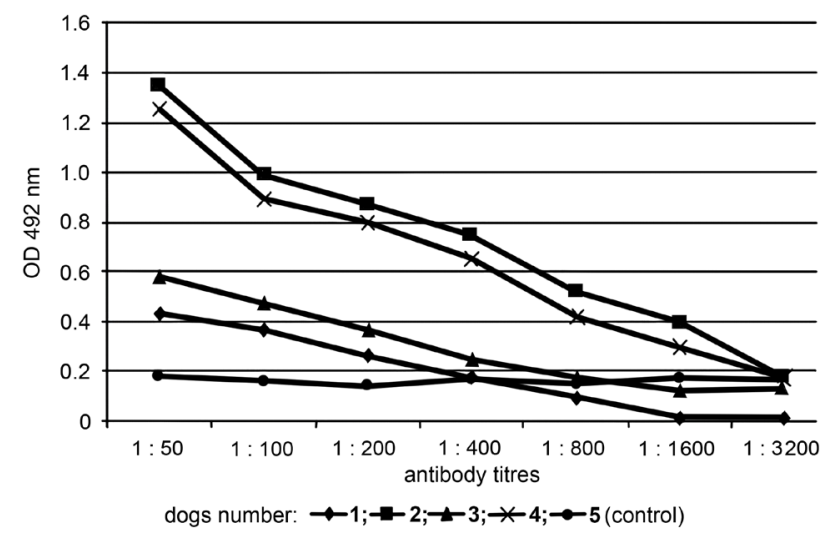

Fig. 5. Serological testing dogs for opisthorchiasis by indirect-ELISA using AIab.

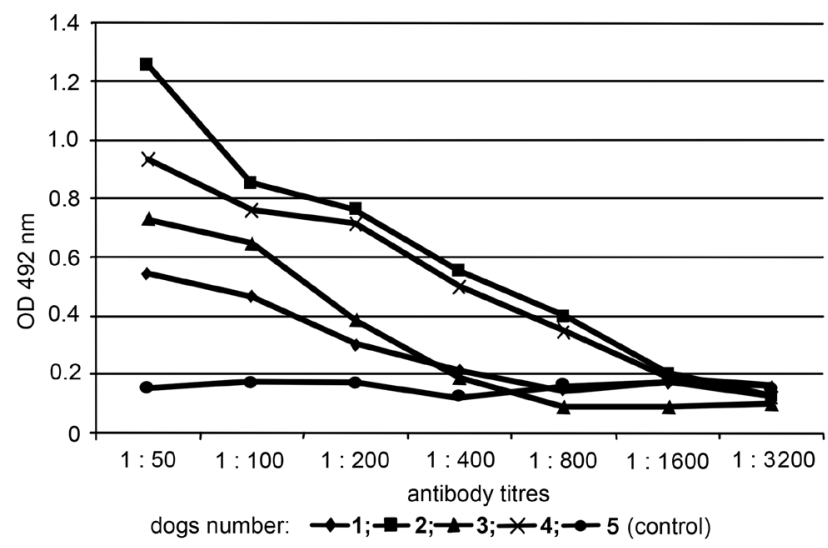

Fig. 6. Serological testing dogs by indirect-ELISA using Opisthorchis felineus ES-Ag.

Table 4. Detection of specific antibodies in sera of dogs against AIab $4 \mathrm{H} 10$ by competitive-ELISA.

\begin{tabular}{lcc}
\hline Dog number & $\begin{array}{c}\text { Mean OD of the wells } \\
\text { coated with AIab }\end{array}$ & Result of competitive-ELISA \\
\hline 1 & $0.024 \pm 0.03$ & positive \\
2 & $0.012 \pm 0.02$ & positive \\
3 & $0.056 \pm 0.04$ & positive \\
4 & $0.065 \pm 0.04$ & positive \\
5 (control) & $2.358 \pm 0.19$ & negative \\
\hline
\end{tabular}

Note: Each serum sample was tested in triplicate.

9 post-immunisation, which corresponds to days 19 and 22 of immunisation, respectively. On day 18 post-immunisation, the specific antibodies in the blood of mice of both groups were not detected. Thus, Alab was able to provoke an immune response and synthesise anti-anti-idiotypic antibody $\left(\mathrm{Ab}_{3}\right)$, which proves its immunogenicity.

Antibodies of the infected dogs were specific to AIab and also liver fluke ES-Ag (Figs. 5, 6). Besides, according to the titres of specific antibodies, AIab was not inferior to ES-Ag by its antigenicity. The present study also shows that the antibodies of the infected dogs recognise AIab as the 'internal image' of $O$. felineus antigen epitope because of a substantial difference between the OD value of infected dogs 1-4 and control dog 5 (Table 4).
For instance, the OD readings of infected dogs were in a range of 0.024 to 0.065 demonstrating their competition with the enzyme-labeled MAb 4B3D9 for AIab. In contrast, in the well with control serum, conjugate reacted freely with its anti-idiotype indicating OD more than 36 times higher than that of infected dogs. Thus, our serological testing studies demonstrate a possibility of application of the competitive-ELISA based on AIab for the detection of specific antibodies of $O$. felineus.

\section{DISCUSSION}

In the present study we selected two hybridoma clones that produced MAb of classes G and M. Antibody avidity depends on affinity as well as the number of antigen binding sites, and in the case of equal affinity, $\operatorname{IgM}$ has superior as it is a pentamer (Khaitov 2011). Hence, a sandwich ELISA was developed by using MAb 4B3D9 as 'capture' antibody for liver fluke-specific antigen. The principle of finding specific antibodies in human serum was based on the selective sensitisation of the solid phase with specific protein from the composition of ES-Ag by MAb.

In the later stages of opisthorchiasis CIC are formed. Therefore, such immune complexes can be determined by other antibodies specific to free epitopes of the antigen. MAb was also used as 'capture' antibody for CIC. The examinations of human sera in comparison with commercial tests demonstrated that the epitope of MAb is located within the parasite protein with a molecular mass of $28 \mathrm{kDa}$. This protein was detected by MAb in ELISA as well as in the SA of $O$. felineus, but with a lower intensity. Apparently, it is due to its relatively low concentration on the solid phase as compared with ES-Ag. Glutathione S-transferase (GST), a $28 \mathrm{kDa}$ protein, was found in the excretion/ secretion product of Opisthorchis viverini (Poirier, 1886) but GST was not useful as a diagnostic reagent in established infections in humans and hamsters (Eursitthichai et al. 2010).

$F(a b)_{2}$ of MAb 4B3D9 specific for an epitope on $O$. $f e-$ lineus ES-Ag conjugated with colloidal gold turned out to be an effective immunogen for obtaining AIab. Selection of colloidal gold nanoparticles for preparation of the conjugate with $F(a b)_{2}$ fragment is explained by the fact that in contrast to other known carriers it does not cause antibody production and has more prominent immune simulating properties. Gold preserves the composition of molecules attached to it and facilitates presentation in unmodified form to the cells responsible for immunity (Dykman and Khlebtsov 2012). As a result of cell fusion, hybrid strain $4 \mathrm{H} 10$ producing AIab to MAb's $F(a b)$, was created. AIab, mimicking an epitope of O. felineus ES-Ag, had the capacity to bind specific antibodies and elicit an immune response in the form of antibody formation that indicates the possibility of its use as an antigen in the development of immunoassays for the diagnosis of opisthorchiasis.

AIab was used as a substitute for adult liver fluke antigen in both indirect- and competitive-ELISA on serum samples of dogs experimentally infected with metacercariae of $O$. felineus. Mature trematodes were isolated from all infected animals. In dogs with a relatively small number 
of parasites faecal egg counts were negative, even though antibodies were found in serum by ELISA. This finding demonstrates the importance of serology as an additional tool in the diagnosis of opisthorchiasis.

AIab proved to be an antigen of value in both types of ELISA. However, using the indirect-ELISA for detection of specific antibodies to $O$. felineus requires enzyme-conjugated antibodies against immunoglobulins of various definitive hosts of the parasite. The immunoassay that uses only one type of conjugate is more practical than the other. We used both types of antibody (MAb and AIab) for competitive-ELISA development. The method is based on competition of peroxidase-conjugated MAb 4B3D9 with the specificity to parasite ES-Ag, and test serum antibodies for AIab adsorbed on the solid phase. AIab can be used in the ELISA as an alternative to the native $O$. felineus ES-Ag.
In additon, experimental animals are not required and time-consuming steps of antigen preparation are reduced. The substitution of ES-Ag antigen with AIab will allow increased specificity of the ELISA.

Acknowledgments. The authors are grateful to S.K. Atygaeva (Astana Infectious Diseases Hospital, Astana, Kazakhstan) who provided serum samples from patients suspected of contracting infectious diseases and Orken S. Akibekov, Lyudmila A. Lider (S. Seifullin Kazakh Agro-Technical University, Astana, Kazakhstan), Sadibek S. Tokpan (National Veterinary Laboratory, Astana, Kazakhstan) for their technical support to test fish for the presence of metacercariae and infect dogs. We are also indebted to Sara O. Kitaibekova for the revision of the manuscript. This investigation was financially supported by the Ministry of Education and Science of the Republic of Kazakhstan within the framework of the projects Nos. 0109RK00476 and 0112 RK01353 for 2009-2011 and 2012-2014, respectively.

\section{REFERENCES}

Amornpunt S., Sarasombath S., Sirisinha S. 1991: Production and characterization of monoclonal antibodies against the excretory-secretory antigen of the liver fluke (Opisthorchis viverrini). Int. J. Parasitol. 21: 421-428.

An L.L., Hudson A.P., Prendergast R.A., O’Brien T.P., StuARt E.S., Whittum-Hudson J.A., MacDonald A.B. 1997: Biochemical and functional antigenic mimicry by a polyclonal anti-idiotypic antibody for chlamydial exoglycolipid antigen. Pathobiology 65: 229-240.

Armignacco O., Ferri F., Gomez-Morales M.A., Caterini L., Pozio E. 2013: Cryptic and asymptomatic opisthorchiasis. Am. J. Trop. Med. Hyg. 88: 364-366.

Beatty J.D., Beatty B.G., Vlahos W.G. 1987: Measurement of monoclonal antibody affinity by non-competitive immunoassay. J. Immunol. Methods 100: 173-179.

Borovikov S.N., Koybagarov M.A., Suranshiev Zh.A., Baesheva D.A., Atygaeva S.K., Khalikova A.S. 2010: [Preparation and study of immunochemical properties of Opisthorchis felineus antigens] Biotech. Theory Prac. 4: 70-74. (In Russian.)

Bulashev A.K., Borovikov S.N., Koybagarov M.A., SuranShiev Zh.A., Lider L.A., Baesheva D.A., Atygaeva S.K., Serikova Sh., Khalikova A.S., Sutula M.Y. 2011 inventor; S.Seifullin Kazakh Agro-Technical University, assignee. [Method of preparation of excretory-secretory antigen for serological diagnosis of opisthorchiasis.] Republic of Kazakhstan patent KZ 68176. Apr 15. (In Russian).

Bulashev A.K.,Borovikov S.N., Koybagarov M.A.,AkibeKov O.S., Suranshiev Zh.A., Tokpan S.S. 2012 inventor; S.Seifullin Kazakh Agro-Technical University, assignee. [Method of preparation of excretory-secretory antigen for serological diagnosis of larval echinococcosis.] Republic of Kazakhstan patent KZ 73428. Mar 15. (In Russian).

Dykman L.A., Khlebtsov N. 2012: Gold nanoparticles in biomedical applications: recent advances and perspectives. Chem. Soc. Rev. 41: 2256-2282.

Dykman L.A., Sumaroka M.V., Staroverov S.A., Ză̌tseva I.S., BogatyreV V.A. 2004: [Immunogenic properties of colloidal gold.] Izv. Acad. Sc. Biol. Ser. 1: 86-91. (In Russian.)

Eursitthichai V., Viyanant V., Tesana S., Sithithaworn P., Kosa N., Grams R. 2010: Opisthorchis viverrini: evaluation of $28 \mathrm{kDa}$ glutathione S-transferase as diagnostic tool in human opisthorchiasis. Acta Trop. 114: 76-80.

FÜlleborN F. 1920: Neuere Methoden zum Nachweis von Helmintheneiern. Arch. Schiffs. Tropenhyg. 24: 174-175.

Gómez-Morales M.A., Ludovisi A., Amati M., Pozio E. 2013: Validation of an excretory/secretory antigen based-ELISA for the diagnosis of Opisthorchis felineus infection in humans from low trematode endemic areas. PLoS ONE 8: e62267.

Hayunga E.G., Sumner M.P., Duncan J.F. Jr., Chakrabarti E.K., Webert D.W. 1992: Production of anti-idiotypic antibodies as potential immunoreagents for the serological diagnosis of bovine cysticercosis. Ann. N. Y. Acad. Sci. 653: 178-183.

Johansen M.V., Sithithaworn P., Bergquist R., Utzinger J. 2010: Towards improved diagnosis of zoonotic trematode infections in Southeast Asia. Adv. Parasitol. 73: 171-195.

Khaitov R.M. (Ed.) 2011: [Immunology.] GEOTAR-Media, Moscow, 528 pp. (In Russian.)

Kohler G., Milstein C. 1975: Continuous cultures of fused cells secreting antibody of predefined specificity. Nature 256: 495497.

LAEмmli U.K. 1970: Cleavage of structural protection during the assembly of the head of bacteriophage T4. Nature 227: 680-685.

Laferrière C., Peeling R.W., Tackaberry E.S., Hamel J., Dillon J.A., Brodeur B.R. 1993: A novel approach to the laboratory diagnosis of Chlamydia trachomatis infections using monoclonal anti-idiotypic antibodies. J. Immunol. Methods 163: 123-131.

Lepekhin A.V., Ratner G.M., Meniavtseva T.A. 1990: [Cross-reacting antigens of Opisthorchis felineus and Salmonella typhi and their possible effect on the clinical course of typhoid fever.] Med. Parazitol. (Mosk.) 4: 33-36. (In Russian.)

Li B., Peng J., Niu Z., Yin X., LiU F. 2005: Preparation of anti-idiotypic antibody against avian influenza virus subtype H9. Cell Mol. Immunol. 2: 155-157.

Mitchell G.F., Garcia E.G., Cruise K.M. 1983: Competitive radioimmunoassays using hybridoma and anti-idiotype antibodies in identification of antibody responses to, and antigens of, Schistosoma japonicum. Aust. J. Exp. Biol. Med. Sci. 61: 27-36.

Nakane P.K., Kawaoi A. 1974: Peroxidase-labeled antibody. A new method of conjugation. J. Histochem. Cytochem. 22: 10841091.

Pozio E., Armignacco O., Ferri F., Gomez Morales M.A. 2013: Opisthorchis felineus, an emerging infection in Italy and its implication for the European Union. Acta Trop. 126: 54-62.

Sakolvaree Y., Ybanez L., Chaicumpa W. 1997: Parasites elicited cross-reacting antibodies to Opisthorchis viverrini. Asian Pac. J. Allergy Immunol. 15: 115-122.

SAYduldin T.S. (Ed.) 1992: [Basics of serology]. Gylym, A1ma-Ata, Kazakhstan, 272 pp. (In Russian.)

Sripa B., KaEwkes S. 2000: Relationship between parasite-specific antibody responses and intensity of Opisthorchis viverrini infection in hamsters. Parasite Immunol. 22: 139-145. 
Starkova T.V., Poletaeva O.G., Kovrova E.A., Krasovskaia N.N., Tkachenko T.N., Masiago A.V., Ofitserov V.I., TereshCHENKoA.Iu. 2011: [The efficiency of the enzyme immunoassay test system opisthorchiasis-CIC-EIA-best to detect circulating immune complexes containing Opisthorchis antigens in the serum of patients with opisthorchiasis.] Med. Parazitol. (Mosk.) 3: 44-45. (In Russian.)

Teplukhin Iu.V., Karal'nik B.V., Kuz'min Iu.A., GorbunovA L.A. 1990: [Antigenic preparations from Opisthorchis and their use in immunodiagnosis. 2. The effectiveness of antibody detection in infected patients.] Med. Parazitol. (Mosk.) 4: 46-48. (In Russian.)

Thu N.D., Dalsgaard A., Loan L.T., Murrell K.D. 2007: Survey for zoonotic liver and intestinal trematode metacercariae in cultured and wild fish in An Giang Province, Vietnam. Kor. J. Parasitol. 45: 45-54.

Toledo R., Esteban J.G., Fried B. 2012: Current status of foodborne trematode infections. Eur. J. Clin. Microbiol. Infect. Dis. 31: $1705-1718$.

Towbin H., Staehelin T., Gordon J. 1979: Electrophoretic transfer of proteins from polyacrylamide gels to nitrocellulose sheets: procedure and some applications. Proc. Natl. Acad. Sci. USA 76: 4350-4354.

Received 29 February 2016

Accepted 4 May 2016
Traverso A., Repetto E., Magnani S., Meloni T., Natrella M., Marchisio P., Giacomazzi C., Bernardi P., Gatti S., Gomez Morales M.A., Pozio E. 2012: A large outbreakof Opisthorchis felineus in Italy suggests that opisthorchiasis develops as a febrile eosinophilic syndrome with cholestasis rather than a hepatitis-like syndrome. Eur. J. Clin. Microbiol. Infect. Dis. 31: 1089-1093.

Waldmann H., LefKovits I. 1984: Limiting dilution analysis of cells of the immune system II: what can be learnt? Immunol. Today 5: 295-288.

WHO 1995: Control of foodborne trematode infections. Report of a WHO study group. World Health Organ Tech. Rep. Ser. 849: 92-93.

Wu Y.Q., Tao R.H., Qiu Z.N., Luo Q.P., Guan X.H., Wu G.L., ZhaO W.X. 1993: [A study on the monoclonal anti-idiotypic antibody NP30 for the diagnosis of schistosomiasis japonica.] Parasitic Doctrine and Parasitic Diseases in China 11: 195-197. (In Chinese.)

Zhou E.M., HuAng W. 1995: Anti-idiotypic antibody as potential serodiagnostic reagent for detection of bluetongue virus infection. J. Clin. Microbiol. 33: 850-854.

Cite this article as: Bulashev A.K., Borovikov S.N., Serikova S.S., Suranshiev Z.A., Kiyan V.S., Eskendirova S.Z. 2016: Development of an ELISA using anti-idiotypic antibody for diagnosis of opisthorchiasis. Folia Parasitol. 63: 025. 